\section{Transformation of the Interface: Future of Human-Building Interactions}

Fatih Topak ${ }^{1}$, ORCID: 0000-0002-0561-359X

Mehmet Koray Pekeriçli², ORCID: 0000-0001-5888-4265

\section{Keywords}

Human-Building Interactions; Building Interfaces; Intelligent Buildings; Occupant Behaviors

\section{Article Information}

Received:

03.11.2020

Received in Revised Form:

15.12.2020

Accepted:

25.12.2020

Available Online:

30.01 .2021

Article Classification:

Research Article

\section{Highlights}

- Human-building interactions in conventional buildings are reviewed.

- A transformation scenario for the building interface is outlined.

- Potential contextual differences in intelligent buildings are discussed.

\section{Contact}

1. Department of Architecture, Middle East Technical University, Ankara, Turkey ftopak@metu.edu.tr

2. Department of Architecture, Middle East Technical University, Ankara, Turkey -

koray@metu.edu.tr 


\section{Arayüz Dönüşümü: Gelecekteki İnsan-Bina Etkileşimleri}

Fatih Topak ${ }^{1}$, ORCID: 0000-0002-0561-359X

Mehmet Koray Pekeriçli², ORCID: 0000-0001-5888-4265

\section{$\ddot{O} z$}

Binalar, dünyadaki toplam enerji kullanımının yaklaşık \%40'ından sorumludur ve bu oran, araştırmacıları yapı sistemlerinin işletilmesi ve kullanılması için yeni yollar üzerinde çalışmaya iten ciddi çevresel kaygılara yol açmaktadır. Akıllı binaların birçok yenilikçi özelliğe sahip son teknoloji ürünleriyle donatılı olacağı değerlendirildiğinde, akıllı binaların insanlarla arasındaki etkileşimlerin geleneksel binalardan farklı olacağı öngörülmektedir. Uzun yillar boyunca, basit mantık ve fiziksel ara yüzleriyle kullanıcıya karşı neredeyse tamamen şeffaf olan temel bina bileşenleri, bina sakinlerine sıcaklık, aydınlatma ve hava kalitesi dâhil olmak üzere iç mekân çevre koşullarını düzenlemek için gelişmiş fırsatlar sağlamıştır. Bununla birlikte, binaların yakın gelecekte alandaki gelişmelerle birlikte daha fazla otomasyon, akıllı uygulamalar ve yapay zekâyı bünyesine katması beklendiğinden, geleneksel bina ile etkileşim modalitelerinin değişime tabi olacağı ve insanların yapılarla etkileşiminde radikal bir geçiş olacağ1 öngörülmektedir. Bu araştırma insan-bina etkileşimlerindeki mevcut durumu incelemeyi ve bu alandaki gelişmelere atıfta bulunarak gelecekteki olası değişimlerin ana hatlarını belirlemeyi amaçlamaktadır.

\section{Öne Çıkanlar}

- Geleneksel yapılarda insan-bina etkileşimleri incelendi.

- Bina arayüzleri için bir dönüşüm senaryosu çerçevesi çizildi.

- Akıllı yapılardaki olası bağlamsal farklılıklar tartışıldı.

\section{Anahtar Sözcükler}

İnsan-Bina Etkileşimleri; Yap1 Arayüzleri; Akıllı Binalar; Bina Kullanıcı Davranışları

\section{Makale Bilgileri}

Alind1:

03.11.2020

Revizyon Kabul Tarihi:

15.12.2020

Kabul Edildi:

25.12.2020

Erişilebilir:

30.01 .2021

Makale Kategorisi:

Özgün Araştırma Makalesi

\section{İletişim}

1. Mimarlık Bölümü, Orta Doğu

Teknik Üniversitesi, Ankara, Türkiye-ftopak@metu.edu.tr

2. Mimarlık Bölümü, Orta Doğu

Teknik Üniversitesi, Ankara,

Türkiye-koray@metu.edu.tr 


\section{GİRİŞ (INTRODUCTION)}

İnşaat sektörünün dünya genelinde toplam birincil enerji tüketimindeki pay $1 \% 40$ 'a ulaşmıştır (EIA, 2017). Binaların atmosfere salınan karbondioksit emisyonundaki payı yaklaşı $\% 20$ 'dir ve bu da yaşam döngüleri boyunca yoğun bir sera etkisi yaratmalarına yol açmaktadır (IPCC, 2015). Binalar ile ilgili artan çevresel kayg1lar kritik bir seviyeye geldiğinden, inşaat sektörü için yeni iyileştirme gereksinimleri ortaya çıkmaktadır. Literatürde mekanik iklimlendirme sistemlerinin optimizasyonu, termal modelleme, yeni enerji yönetimi model önerileri ve bina cihazlarının otomasyonu da dâhil olmak üzere binalarda enerji verimliliğini artırmak için çeşitli yaklaşımlar bulunmaktadır (Chen ve Treado, 2014; Kwong, Adam ve Sahari, 2014; Yang ve Wang, 2012). Sensörlerle alg1lama, aktive etme, bilgi ve otomasyon teknolojilerinde son yıllarda hızlı ve yoğun gelişmeler yaşanırken, binaların insanlara çevre üzerindeki olumsuz etkilerini azaltarak hizmet edebileceği yeni kompleks sistemler uygulanabilir hale gelmiştir. Dahası, teknolojik araçları binaların dokusuna dâhil etmek, mimarlar ve mühendisler tarafından gelecekteki yapılı çevrenin dinamik zorluklarıyla başa çıkmak için gelişmiş mekânlar yaratmanın bir yolu olarak kabul edilmektedir (Dalton, Schnädelbach, Wiberg ve Varoudis, 2004).

İklim değişikliği ile mücadele ve kritik küresel enerji tüketimini azaltma hedeflerine ulaşma yönündeki dürtü ile teknolojik ilerlemelerin binaların tüm yaşam döngüsü aşamalarına entegrasyonu için farklı yollar aramak büyük bir araştırma alanı haline gelmiştir. Sensörle algılama ve aktive etme teknolojilerindeki maliyet düşüşü ve bina otomasyon sistemlerinin yaygınlaşması, yapılı çevre için yakın gelecekte yaşanması muhtemel derin değissikliklerin işaretleri olarak görülebilirler. Aslında, binaların çeşitli teknolojilerle dijitalleştirilmesi ve etkileşimli nesneler haline gelmeleri geleceğin bir probleminden ziyade bugünün bir gerçeğidir ve bu gerçeğin etkileri, insanları ve insanların binaları kullanım şekillerini de dikkate alacak metodlarla çalışılmalıdır (Nembrini Ve Lalanne, 2017). Binalar zaman içerisinde insanlara barınak sağlayan temel yapılardan, farklı bilimsel alanların birlikte çalışmasını gerektiren karmaşı sistemlere evrilmişlerdir ve gelecek nesil yapılı çevreyi oluşturmak adına araştırmalar birçok farklı disiplinin katkısıyla devam etmektedir. (Lilis, Conus, Asadi ve Kayal, 2017). Öte yandan, insanlar zamanlarının yaklaşı \% \% 9 'ını yapılı çevrenin kapalı alanlarında (ev, okul, ofis gibi) geçirdiklerinden, binaların insan yaşam alanı olarak görevlerini tam anlamıyla yerine getirmeleri beklenir. İnsanların içerisinde yaşamlarını sürdürdükleri binaların temel görevi, konforlu ve sağlıklı iç mekânlar sağlamaktır. Bu bağlamda, yapılı çevrede gerçekleşecek olan teknolojik 
değişimlerde bina kullanıcıları ana özne olarak düşünülmeli ve bu yöndeki öneriler insan odaklı bir yaklaşımla geliştirilmelidir.

Bir yapı içerisinde zaman geçiren insanlar, çeşitli bireysel ve bağlamsal sebeplerle çevreleriyle etkileşime girerek hem enerji tüketimine hem de iç mekân koşullarının kalitesine katkıda bulunurlar. Konvansiyonel binalarda, temel bina bileşenleri basit mantık ve fiziksel ara yüzleriyle (aydınlatma lamba düğmeleri, pencere açma kolu gibi) insanlara iç mekân çevre koşullarını düzenlemek için gelişmiş fırsatlar sağlamıştır. Bununla birlikte, yakın gelecekte binaların daha fazla otomasyon, akıllı uygulamalar ve yapay zekâyı bünyesine katması beklendiğinden, geleneksel insan-bina etkileşim modalitelerinin değişime tabi olacağ ve etkileşim arayüzlerinde radikal bir dönüşüm olacağ1 düşünülmektedir. $\mathrm{Bu}$ araştırma insan-bina etkileşimlerindeki mevcut durumu incelemeyi ve bu alandaki gelişmelere atıfta bulunarak gelecekteki olası değişimlerin ana hatlarını belirlemeyi amaçlamaktadır.

\section{AKILLI BİNALAR (INTELLIGENT BUILDINGS)}

Yapılı çevreler, insanların fiziksel olarak sarmalandığı ve davranışlarının etkilerini her açıdan duyumsadığı etkileşimli bağlamlardır. Her ne kadar konvansiyonel yapıların temel rolleri farklı insan faaliyetlerini desteklemek olsa da, statik yapıları sebebiyle sürekli değişen insan ihtiyaçları ile başa çıkmakta yetersiz kalmakta ve bu konuda başarısız olmaktadırlar. Bağlama bağlı olarak, bina kullanıcılarının binalardan mahremiyet, konfor, emniyet, sessizlik, 1şıklandırma, sağlıklı koşullar, enerji verimliliği, geri dönüşüm, iletişim kolaylığı ve eğlence gibi farklı beklentileri bulunabilir. İnsanlar, fizyolojik (cinsiyet, yaş vb.), psikolojik ve kültürel faktörlere dayanarak, farklı konfor tercihlerine, memnuniyet seviyelerine ve iç ortam algılarına sahip olabilirler (Indraganti ve Rao, 2010). Gelişmiş sensör ve harekete geçirme teknolojilerine sahip binaların, yapı sistemlerinin konfor odaklı ayarlamalarında daha fazla esneklik sağladığı ve bunun da enerji harcamalarında bir düşüş gerçekleştirdiği bilinmektedir (D’Oca, Hong ve Langevin, 2018). Genel olarak, teknolojik ürün ve sistemlerin yapılı çevreye entegrasyonu ve bu doğrultuda iyileştirmeler yapmak üzere yürütülen çalışmalar literatürde "akıllı binalar" şemsiye terimi altında incelenmektedir.

Akıllı binalara olan ilgi ilk olarak 1980'lerde başlamıştır ve "akıllı binalar" teriminin ilk tanımları neredeyse tamamen teknoloji entegrasyonu ve bina otomasyonu ile ilişkilendirilmiştir. Ak1llı bina olarak tarif edilen ilk örneklerin çoğu, yalnızca artan miktarda bilgi teknolojisi ürünlerinin varlığını temsil etmiştir (Wigginton ve Harris, 2002). Daha sonra akıllı bina konseptinin tanımı, bina kullanıcıları, bina sistemleri ve çevre arasındaki bağlantıyı kapsayacak şekilde genişletilmiştir. Akıllı binalar araştırmalarının ana odağı zamanla teknoloji entegrasyonu arayışından bina kullanıcılarının beklentilerine yanıt vermek, konfor ihtiyaçlarını karşılamak ve yaşam kalitelerini artırmak gibi konulara doğru evrilmiştir. Bu evrilme, 1980’lerden sonra bina sistem kontrollerinin teknolojik bir dönüşüm geçirmesine parallel olarak ortaya çıkan progresif gelişmelerin bir sonucu olarak değerlendirilebilir. Bilgisayar, elektronik ve bilgi teknolojilerinde kısa sürede yaşanan sıçramalar yapılı çevrede de etkisini göstermiş, ve 2000li yılların başından itibaren teknoloji entegrasyon çalışmalarının kapsamı genişleyerek akıllı binalar ve akıllı şehirler seviyesine gelmiştir (Şekil 1). Son yirmi yılda yapı ölçeğinde yapılan kapsamlı araştırmalar sonucunda akıllı binalar literatüründe belli bir aşama kaydedilmiş olsa da, pratikteki uygulamalar henüz yeterince olgunlaşamamıştır. 


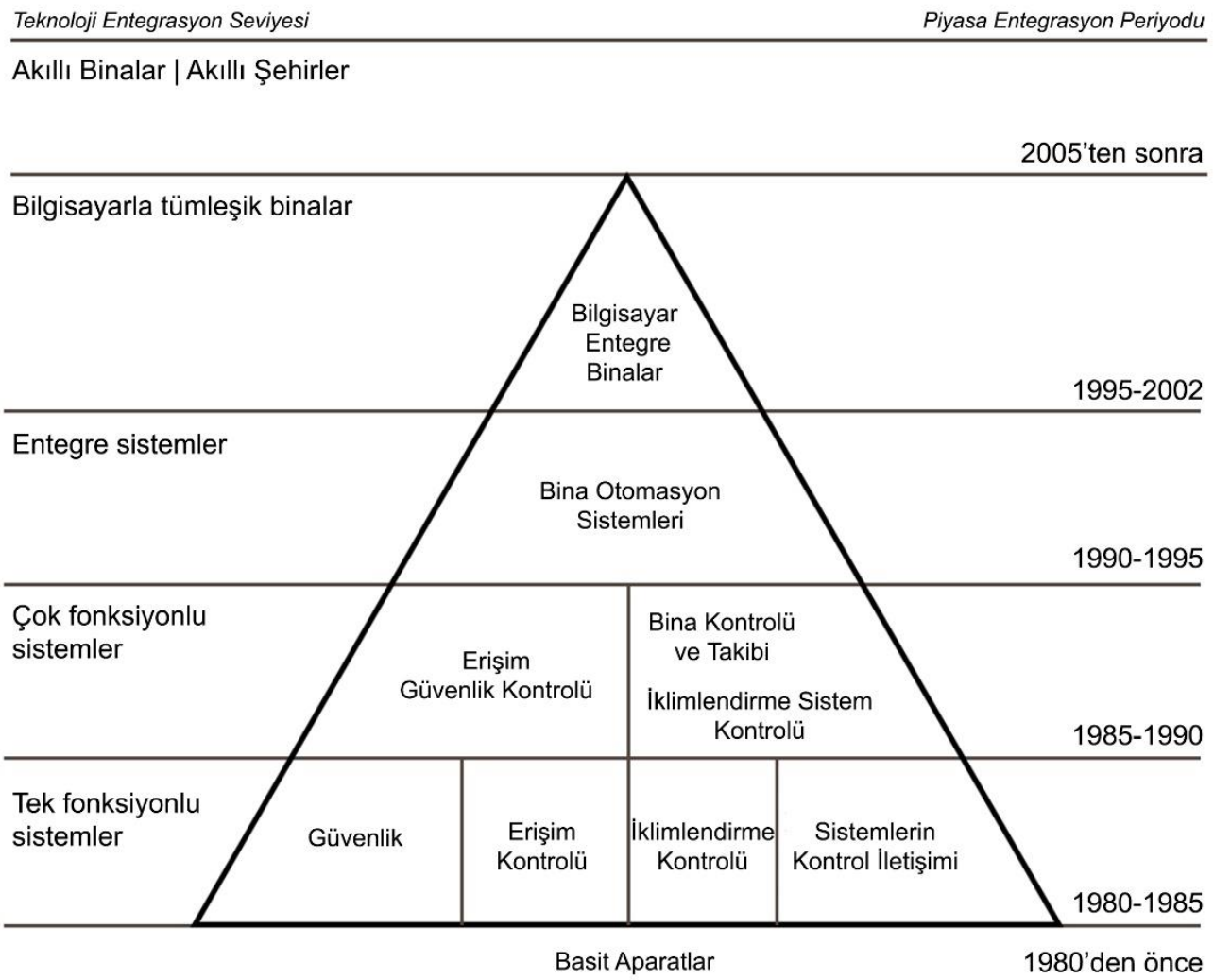

Şekil 1. Akıllı Binalar Pramidi (Uyarlanmış versiyon, Wang (2010))

Kavramsal gelişimi, bina kullanıcıları için enerji verimli, üretken ve çevre açısından sağlıklı ortamlar oluşturmak ve bina sistemleri yönetimini optimize etmek üzerine dayanan akıllı binaların, kritik yap1 parametrelerini (sıcaklık, 1şık, ses vb.) otomatik ve dinamik bir şekilde komuta ederek sürekli değişen insansal ve çevresel ihtiyaçları destekleyebilecekleri öngörülmüştür. Akıllı binalarda, birçok yap1 bileşeninin etkileşimine izin veren sistem entegrasyonu, insanların, süreçlerin ve ürünlerin etkileşimli olarak değerlendirilmesini gerektirir (Clements-Croome, 2013). Bununla birlikte, akıllı binaların çalışma hassasiyeti insan faaliyetleri ve davranışları hakkında doğru bilgi akışına bağlı olmasına rağmen, binaları akıllı hale getirme girişimlerinin çoğu, insan-bina arasındaki dinamik ilişkiyi temelde göz ardı ederek, bina bileşenlerinin teknik iyileştirmeleriyle ilgilenmiştir (Lee, 2010). Fakat akıllı bir binanın sadece teknolojik olmak suretiyle hedeflerine ulaşamayacağı açıktır; daha önemli olan, akıllı binaların planlanan kullanım durumuna uygun olmaları ve bir yandan enerji verimliliği sağlarken, bir yandan da insan odaklı rahat bir yaşam veya çalışma ortamı oluşturma fonksiyonunu yerine getirmeleridir (Clements-Croome, 2013). Bu bağlamda, bilgi teknolojisi ve otomasyon sistemlerinin yapı içerisinde zaman geçiren bina kullanıcılarının rahatlı, güven ve kontrol algısını zedelememesi gerekir. İnsan davranışlarının bina enerji tüketimine olan olumsuz etkisi bertaraf edilmeye çalışılırken, bina kullanıcıları için konforlu bir iç mekân oluşturma hedefi de göz ardı edilmemelidir. Atıfta bulunulan durumun, insanlar ve binalar arasında karşıllklı geri bildirime olanak sağlayacak bir diyalog arayüzünün oluşturulması yoluyla optimum bir şekilde sağlanacağı düşünülmektedir. 


\section{BİNA KULLANICI DAVRANIŞLARI VE ETKİLERİ (OCCUPANT BEHAVIORS AND THEIR EFFECTS)}

İnsan davranışlarını ve bu davranışları tetikleyen faktörleri anlamak, insanların kaliteli yaşam standartları altında az tüketen yaşam tarzlarına sahip olmaları öngörülen geleceğin binalarını tasarlamak için büyük bir öneme sahiptir (Schweiker, 2010). Yapılı çevrenin temel öznesi insan olduğundan, binalardaki mevcut koşulların iyileştirilmesine yönelik her girişimin en önemli girdisi insan faktörü olmalıdır. İnsanlar, bilinçli ve kasıtlı bir şekilde yapılı çevreleriyle etkileşime girerek hem enerji tüketimine hem de iç mekân koşullarının kalitesine katkıda bulunurlar (Grabe ve Gonzalez, 2016). İnsan davranışları çok katmanlı ve karmaşıktır, ve hem aynı ortamdaki diğer insanları hem de binaları etkilerler. İnsan davranışının stokastik yapısından dolayı, insanların çevreleriyle girecekleri etkileşimleri önceden tahmin etmek zordur. İnsan davranışlarının ve etkileşimlerinin dikkate alınması, bina sistemlerinin performansını optimize etmenin etkili bir yolu olarak vurgulanmış (Thomas ve Pasquier, 2015) ve bina enerji tüketiminde \%20'ye kadar düşüş sağladığ1 gösterilmiştir (Klein ve ark., 2012). Ayrıca, D’Oca ve ark. (2018) binaların yaşam döngüsü boyunca insan faktörünü önemli bir girdi olarak dikkate almanın potansiyel faydalarını, bina sakinleri için geliştirilmiş konfor koşulları ve verimlilik, bina sahipleri için işletme maliyetlerinde azalma, bina işletmecileri ve enerji yöneticileri için daha etkin bina enerji yönetimi ve otomasyon sistemleri olarak sıralamıştır.

İnsanların yaşadıkları çevrelerinden bazı konfor beklentileri vardır ve bu beklentiler karşılanmadığında, çevreleriyle etkileşime girerek ortamı kendilerine adapte edecek (örneğin; bir pencere açmak) veya kendilerini ortama adapte edecek (örneğin; kıyafet değiştirmek) eylemler gerçekleştirirler. Bununla birlikte, kişisel konfor kriterleri bağlamsal ve çevresel faktörlere bağlıdır ve statik konfor profilleri genel bir ortalamayı yansıtmaktan öteye gitmemektedir. Hong ve ark. (2015) insan ihtiyaçlarını fiziksel ve fiziksel olmayan olarak iki kategoride sınıflandırmıştır. Buna göre, fiziksel ihtiyaçlar arasında termal konfor, görsel rahatlık, akustik konfor ve bina içi çevre sağlığ1 bulunurken; fiziksel olmayan ihtiyaçlar ise mahremiyeti, kültürel tercihleri ve günlük rutinleri kapsamaktadır. Termal konfor, bina içi hava sıcaklığı, bağıl nem, mahal hava hızı, aktivite seviyesi ve giysi seviyesi gibi faktörlerin bir birleşimiyken, görsel konfor aşırı parlama, kontrast veya parlakliğa maruz kalmama ile doğrudan ilgilidir. Akustik konfor, arka plan gürültüsü seviyesinin kabul edilebilir bir aralıkta olmasını gerektirirken, iyi bir iç mekân hava kalitesi, bina içi çevre sağlığı için temel gerekliliktir. Fiziksel ve fiziksel olmayan ihtiyaçlar, insanları genel bir memnuniyet seviyesine ulaşmak için yapılı ortamlarla etkileşime girmeye yönlendirir ve bu etkileşimler bina sistemlerinin ve hizmetlerinin çalışmasını doğrudan etkiler.

Genel olarak, insanlar binaları iki şekilde etkilemektedirler. Birincisi varlıklarının doğrudan olan etkisi ve diğeri de bina ile etkileşime girdiklerinde oluşturdukları etkidir. İnsanların binalar ile girdikleri etkileşimler, Hong ve ark. (2017) tarafindan adaptif ve adaptif olmayan davranışlar olarak kategorize edilmiştir. Buna göre, adaptif davranışları gerçekleştirirken, bina kullanıcıları ya iç ortamı kendi ihtiyaçlarına ya da tercihlerine göre uyarlamak için eylemlerde bulunurlar (pencereleri açma / kapama, panjurları indirme, termostat ayarlama, aydınlatmayı açma / kapama gibi); ya da kendilerini çevrelerine göre uyarlarlar (kıyafetlerini değiştirme gibi). Öte yandan, insanların varlığı ve çeşitli konforsuz durumlara ilişkin şikâyetlerin bina yöneticilerine bildirilmesi gibi adaptif olmayan 
eylemler de nihai bina performans1 üzerinde bir etkiye sahiptir. Ekwevugbe (2013), hem adaptif davranışların, hem de insanların varlığının (karbondioksit, su buharı, vücut 1sısı, ses ve koku salımı yoluyla) iç ortam koşullarına katkıda bulunduğunu belirtmiştir. Şekil 2'de özetlendiği gibi, binaların enerji performansı ve iç mekân konfor seviyeleri, hem insanların varlığından (pasif etkiler) hem de çevreleriyle olan etkileşimlerinden (aktif etkiler) etkilenir.

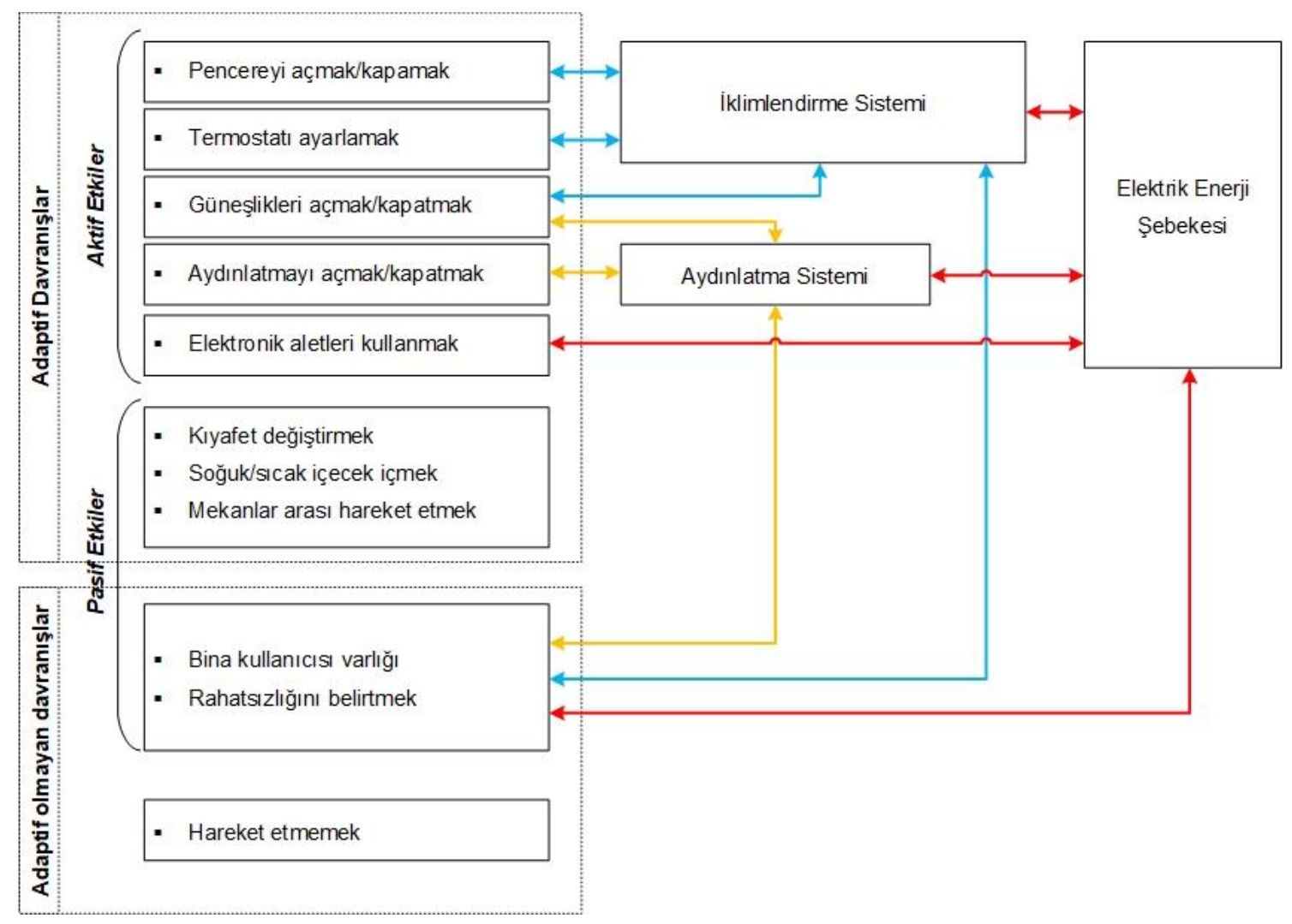

Şekil 2. Bina Kullanıcılarının Davranışları ve Bina Sistemleri Üzerindeki Etkileri

İnsan davranışı, kişisel rahatllğı sağlamak amacıyla yapılı çevrenin fiziksel parametrelerini kontrol etmek için gerçekleştirilen doğrudan veya dolaylı eylemlerin bütünü olarak tanımlanabilir. Humphrey ilkesinin de belirttiği gibi: "Bir ortamda rahatsızlık yaratacak bir değişiklik olursa, insanlar kendi konforlarını tekrar sağlamak için reaksiyon gösterirler” (Nicol \& Humphreys, 2002). Gerçekten de, insanların binalarda gerçekleştirdikleri eylemlerin hem termal konfor hem de enerji tüketim verilerine etki ettiği görülmektedir. Temiz hava arzusu ile açılan bir pencere, binanın genel termal dengesini zayıflatabilirken; aşırı parlamayı önlemek için kapalı pozisyona getirilen bir güneş kırıcı, binayı ısıtacak olan değerli güneş ışınlarının kaybına neden olabilir (Wigginton ve Harris, 2002). ABD Enerji Bakanlığ'nın (U.S. Department of Energy, 2011) raporuna göre, bina sakinlerinin fanları/1sıtıcıları aktive etmek veya pencereleri açmak gibi davranışları, Amerika'daki toplam enerji tüketiminin yaklaşı \% $\% 4$ 'ünü oluşturan 1 sıttma ve soğutma enerji yükleri üzerinde önemli bir etkiye sahiptir. Kopenhag'da bina yönelimi, yap1 sistemleri ve yap1 kaplama kompozisyonu bakımından aynı özelliklere sahip 290 konut biriminin analiz edildiği bir çalışmada, 
Andersen (2012) insan davranışlarının enerji tüketiminde üç kata kadar farka neden olduğunu göstermiştir. Ticari yapılarda insan faktörü enerji tüketiminin karanlıkta kalan kısmı olarak kabul edilmektedir (Masoso ve Grobler, 2010). Hong, D'Oca, Turner ve Taylor-Lange (2015) ve Hong, D'Oca, Taylor-Lange ve arkadaşlarının (2015) yayınladıkları iki ardışı makalede, konvansiyonel binalarda insan davranışını temsil eden ve insan davranışını tetikleyen faktörler, insan ihtiyaçları, insanların gerçekleştirdiği eylemler ve insanların etkilediği sistemler olmak üzere dört temel bileşene dayanan ontolojik bir yaklaşımla sunulmuştur.

İnsan davranışı karmaşık yapısı nedeniyle binaların teknolojik bileşenlerinde doğrudan geri bildirimde bulunarak iyileştirmeler sağlayabileceği gibi, akıllı sistemlerin işletilmesinde sorunlara veya duraksamalara da yol açabilir. Örneğin, Lazarova-Molnar ve Mohamed (2017), insanların bina bileşenleriyle her zaman öngörülen şekilde etkileşimde bulunmaması nedeniyle, insan davranışının bina otomasyon sistemlerinin düzgün bir şekilde çalışması için riskli bir girdi olarak görülmesi gerektiğini iddia etmiştir. Buna ek olarak, sıradan bir insanın gelişmiş teknolojik araçlara aşina olmaması, akıllı binalarda insan-yapı etkileşimlerinin uygun olmayan bir biçimde gerçekleşmesine ve sonuç olarak sistem arızalarına sebep olabilir. Bu senaryoda, insanların akıllı bina sistemleri hakkında bilgilendirilmiş olmalarının, akıllı sistemlerin getirilerinden yararlanmaları için önemli olduğu anlaşılmaktadır. Öte yandan, farklı bir perspektiften incelendiğinde, akıllı binalara entegre edilen teknolojik sistemler, insan davranışlarını pozitif yönde manipüle etmek adına bazı avantajlar sağlayabilir. Enerji tüketimine duyarlı insan davranışlarını desteklemek amacıyla, Khashe, Heydarian, Becerik-Gerber ve Wood (2016), akıllı yapılarda insanlar1 sosyal mesajlar ile bilgilendirmenin etkilerini sorgulamışlar ve olumlu sonuçlar sunmuşlardır. Chen ve ark. (2012) tarafından önerilen bir başka modelde, teknolojinin ikna edici özelliklerinin insan davranışında olumlu değişikliklere fayda sağlaması amaçlanmıştır. Bu araştırmanın temel fikri, insan-teknoloji etkileşimlerinden ve veri analizinden oluşan bir geri bildirim mekanizması aracıllğılyla, insanların zihniyetlerini ve davranışlarını binalarda daha fazla enerji tasarrufu sağlamak adına değiştirmeye çalışmak olarak anlatılmıştır. Bu tür uygulamalar, insan davranışlarını ve insanların çevreleriyle olan etkileşimlerini düzenleme ve iyileştirme araçları olarak düşünülebilir. Yüksek düzeyde teknoloji entegrasyonu, ve bina ve insanlar hakkında gerçek zamanlı veri toplama olanağının bu tür senaryoların kesin önkoşulları olduğu tartışılmazdır ve bu iki özellik de yalnızca akıllı binalarda bulunmaktadır. Konstantakopoulos ve ark. (2019), insanlar ve akıllı bina sistemleri arasındaki işbirliğinin önemini vurgulamaktadırlar ve bilgisayar tabanlı metodların kontrol potansiyeliyle, insan etkileşimine açık sistemler tarafindan sağlanan esneklikten birlikte yararlanıldığında, yapı sistemlerinin sağlamlığı ve sürdürülebilirliğinin artırılarak geliştirilebileceğini iddia etmektedirler.

\section{BİNA ARAYÜZÜNÜN DÖNÜŞÜMÜ (TRANSFORMATION OF THE BUILDING INTERFACE)}

Reyner Banham (1969) kitabında, bina kullanıcılarının konfor beklentilerindeki ve bu beklentileri sürekli gelişen teknoloji ile karşılama yöntemlerindeki dönüşümlerin en temel mimari değişiklikler için öncül olduğunu belirtmektedir. Son y1llarda bilgi, iletişim ve otomasyon teknolojilerindeki hızlanan gelişmeler göz önüne alındığında, bina sistemlerinin insanlarla etkileşime izin veren arayüzlerinde keskin bir dönüşüm olacağı tahmin edilmektedir. Akıllı binaların birçok yenilikçi özelliğe sahip çeşitli teknolojik ürünlerle donatılacağı öngörüsü de düşünüldüğünde, insan-yap1 
etkileşimlerinin konvansiyonel binalardan farklı olması kaçınılmaz görünmektedir. Akıllı binalarda, insanların bina sistemleri üzerindeki kontrol hâkimiyeti belirlenen otomasyon seviyelerine ve bina tipolojisine göre değişebilir. İnsanların bir pencere açmasına bile izin verilmeyen bazı senaryolar olabileceği gibi, bina sakinlerinin çok çeşitli yapı bileşenlerine ve uygulamalarına müdahale etmesine izin verilen durumlar da olabilir. Konut yapılarında insanlara daha fazla kontrol imkânı sağlanırken, ticari yapılarda veya eğitim yapılarında insanların binayla olan olası etkileşimleri sınırlandırılabilir. Ayrıca, geleceğin yapılarının yapay zekâyı ve yeni etkileşim biçimleri için çeşitli potansiyelleri barındırması beklendiğinden, insanların bina ile ve bina içinde olan deneyimlerinde çok çeşitli değişikliklerin olması muhtemeldir (Alavi ve ark. 2019). Bader ve ark. (2019) etkileşime açık yapı bileşenlerine sahip akıllı binaların, insan-yap1 etkileşimleri için yeni yöntemlere zemin hazırlayacağını ve konvansiyonel insan-yapı etkileşimlerinin bir değişim geçireceğini göstermişlerdir. Aslında öngörülen bu değişim, hızlı bir büyüme gösteren nesnelerin interneti (Internet of Things, IoT) ürünleriyle birlikte günümüzde de kendini çoktan göstermektedir. Amazon Alexa, Microsoft Cortana, Apple Siri ve Google Assistant gibi sanal asistanlar, bina sakinlerinin çeşitli bina bileşenleriyle etkileşimlerini düzenlemek için bir diyalog zemini oluşturmak amacıyla piyasaya sürülmüsslerdir (Këpuska \& Bohouta, 2018). Bu gelişimin bir sonraki adımının, tüm bina hizmetlerini ve bileşenlerini hem bina sakinlerinden hem de çevre parametrelerinden gelen veri girdilerine dayalı olarak düzenleyen ve işleten ortak bir bina arayüzünün oluşturulması olacağ1 düşünülmektedir. Bu sistemin bina sakinlerinin bireysel tercihlerini ve rutinlerini algilayan ve insan merkezli bina işletimini destekleyen bir yapay zekâ mekanizması içermesi öngörülmektedir. Bina arayüzlerindeki dönüşüm öngörüsü şematik olarak Şekil 3'de gösterilmiştir.

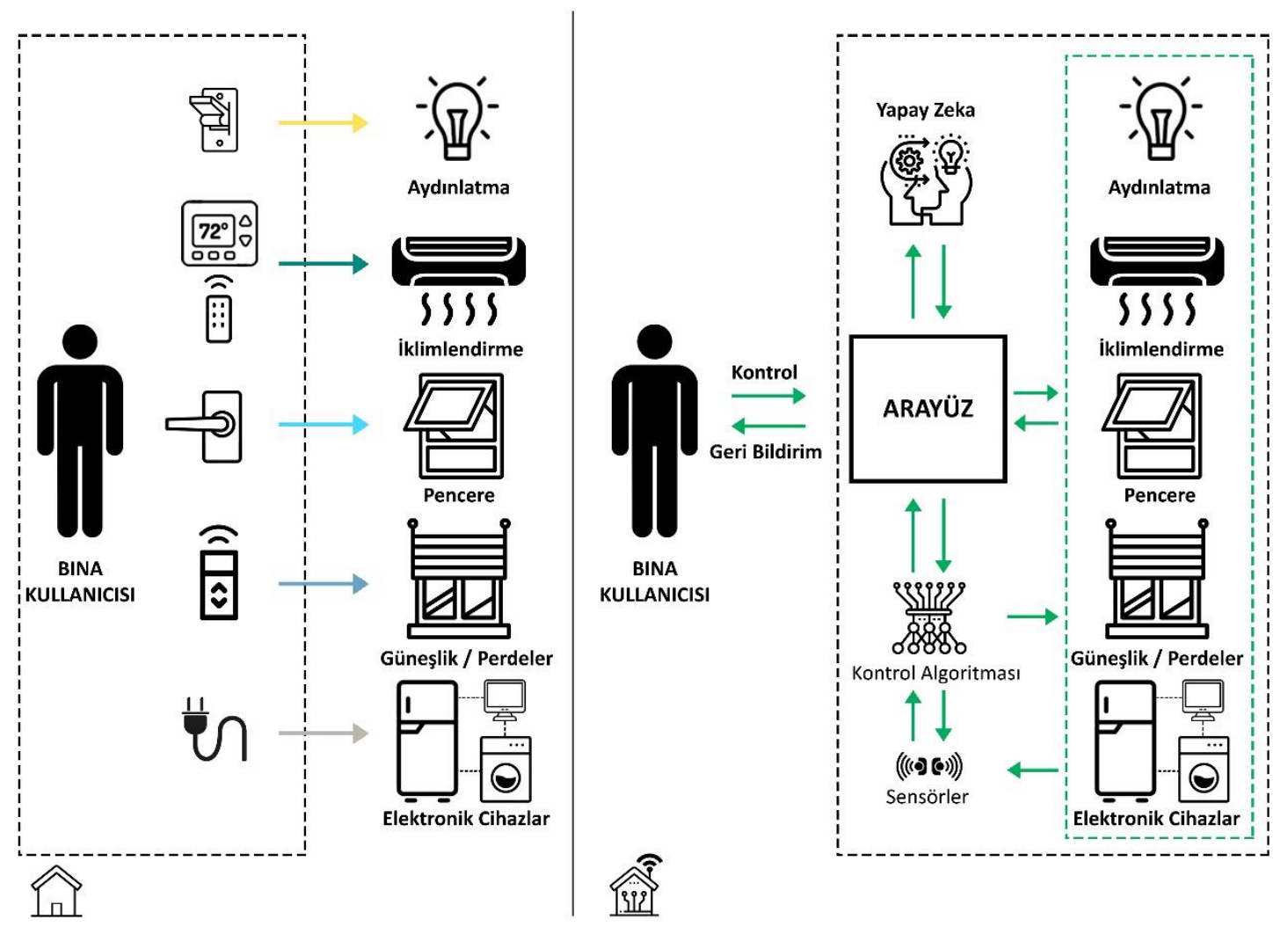

Şekil 3. Bina arayüzlerindeki öngörülen dönüşüm 
Akıllı bina uygulamalarının yapılı çevreye daha yaygın bir şekilde entegre olmasıyla gerçekleşeceği öngörülen arayüz dönüşümünün, bina kullanıcılarına aydınlatma, iklimlendirme, elektronik cihazlar gibi yapı bileşenlerinin yanında, emniyet, güvenlik ve mahremiyeti sağlayabilecek sistemlerin de kontrolü için yeni bir gelişim alanı sağlayacağı düşünülmektedir. Hareket sensörleri, kamera sistemleri, duman-gaz detektörleri, acil sistem alarmları gibi güvenlik ve emniyet amaçlı kullanılan ürünlerin bütüncül bir sistem çalışmasına olanak verecek şekilde geliştirilmesi, kullanıcı tarafindan kolayca kontrol edilebilir olması ve bu konularda kullanıcı deneyimini iyileştirecek yapay zeka algoritmalarının sistem işleyişine entegre edilebilmesi mümkün hale gelecektir.

Son zamanlarda, pek çok çalışma çeşitli veri toplama ve analiz tekniklerini kullanarak insanların bina iç mekânlarında konfor gereksinimlerini (termal, görsel vb.) keşfetmeye odaklanmıştır. Bununla birlikte, Park ve Nagy (2018) tarafindan yapılan kapsamlı bir literatür taramasına göre, konfor araştırmaları ile akıllı bina sistemleri araştırmaları arasında belirli bir kopukluk gözlenmektedir, ve bu iki araştırma alanını birlikte değerlendiren ve bağdaştıran sınırlı sayıda araştırma vardır. Konfor durumu, binalardaki insan davranışının en büyük itici gücü olduğundan (Frontczak ve ark., 2012), araştırmacıların akıllı bina sistemleriyle ilgili yapılan çalışmalarda insan merkezli bir yaklaşıma öncelik vermediği çıkarımı yapılabilir. Mevcut paradigmanın binaların "herkese uyacak tek bir kalıp" yaklaşımıyla işletilmesinden, binaların insan merkezli akıllı yönetimine evrilmesi için, bu iki araştırma alanı arasında daha fazla işbirliğine ihtiyaç olduğu açıktır. Yenilikçi teknolojik araçlara ve yeni tip yapı sistem bileşenlerine sahip akıllı binalar bağlamsal bir farklılığa sahip olacağından, çoğunlukla geleneksel bina sistemleri düşünülerek yürütülen mevcut insan davranışı araştırmalarının, gelecekteki koşullar öngörülerek daha fazla ayrıntılandırılması gerekmektedir. Binaların enerji tüketimi, küresel çevre koşulları, insan sağlığı, refahı ve verimliliği üzerindeki büyük etkisi göz önüne alındığında, bilgi, iletişim, algılama ve harekete geçirme teknolojilerindeki ilerlemeler ile binaların kademeli olarak geçireceği değişimin ve geleceğin akıllı binalarındaki insan-yapı etkileşimlerinin araştırılması büyük önem taşımaktadır.

Teknoloji ürünlerinin yapılara entegre edilmesine yönelik çalışmaların ana ekseni bina kullanıcı konforunu artırmak ve insan hayatını kolaylaştırmak odaklı olsa da, bu eforların farklı boyutlarda yeni tartş̧malar da doğuracağı düşünülmektedir. IoT, büyük veri ve bulut bilişimi kavramlarının insanların yaşamlanında daha fazla yer almasıyla birlikte bir takım gizlilik ve güvenlik risklerinin ortaya çıkacağ1 açıktır. İnsanların günlük yaşantılarının büyük bir bölümünü geçirdikleri yapılı alanlar için teknoloji üreten firmaların, insanlara sunulan teknoloji kapsamı ve insanlardan toplanan veri konularında güvenilir ve denetlenebilir olması, firmaların teknolojik gelişimi yönlendiren tekeller haline dönüşmemesi, ve bu alanda kamusal yararın firmaların çıkarlarının önünde tutulmasının sağlanması, kullanıcıların yeni teknolojilere yaklaşımı konusunda belirleyici rol oynayacağı öngörülmektedir. Teknolojik gelişmelerle birlikte yapılarda ortaya çıkabilecek güvenlik ve mahremiyete yönelik olası riskler Wright ve ark. (2008) tarafindan kitaplarında detaylı bir şekilde sunulmuştur. Avrupa Birliği tarafindan "General Data Protection Regulation (EU GDPR)" ismiyle çıkartılan kapsamlı kanun düzenlemesi, insanlar ile teknoloji üreten firmalar arasındaki ilişkiyi düzenlemek ve firmaların yerine getirmesi gereken sorumlulukları somutlaştırmak üzere 2018 yılından bu yana uygulanmakta ve belli aralıklarla güncellenmektedir. Bu çalışmada öngörülen bina arayüz değişim sürecinin de, bu kapsamdaki çeşitli hassasiyetler ve sorumlulukların getireceği kısıtlamalardan etkileneceği düşünülmektedir. 


\section{SONUÇ (CONCLUSION)}

Hali hazırda, literatürde insanlar ve binalar arasındaki ilişkiyi inceleyen araştırmalar iki başlıkta incelenebilir. İlk başlıkta, araştırmaların önemli bir kısmı bina merkezli bir bakış açısı benimsemekte ve insan davranışlarının binaların enerji performansındaki etkilerini incelemektedir. İkinci başlıkta yer alan araştırmalar ise insan merkezli bir bakış açısı sunmakta ve insanların görsel ve termal konforunu, bina iç mekân çevre kalitesi sorunları ile birlikte incelemektedir. Fakat binaların insan davranışlarını bir geri besleme olarak aldığı ve akıllı kontrol sistemlerini buna göre hem enerji tüketimini optimize etmek hem de rahat yaşam ve çalışma koşulları sağlamak adına düzenleyen olası bir simbiyotik insan-yapı ilişkisi hakkında araştırma eksikliği bulunmaktadır. Her ne kadar sadece insan davranışlarına veya sadece akıllı bina teknolojilerine odaklanan çok sayıda çalışma olsa da, insan davranışları ve akıllı binalar arasındaki iki yönlü dinamik ilişkiyi sorgulayan sınırlı sayıda vizyoner araştırma bulunmaktadır. Bu doğrultuda, bu çalışmada gelişen teknolojiyle birlikte uygulanabilir hale gelebilecek çeşitli bina-insan etkileşim arayüzlerinin araştırılması, insan davranışlarının farklı bina-insan etkileşimine olanak sağlayan mekânlarda incelenmesi ve insan odaklı akıllı bina işletim çerçevelerinin oluşturulması gibi konuların potansiyeli vurgulanmıştır. Hali hazırda farklı bina-insan etkileşimine olanak sağlayacak donanıma sahip ve deney için kullanılabilecek yapı bulunamadığından, yerinde yapılacak incelemeler ve gözlemler çalışmanın kapsamına dâhil edilememisstir. Yazarlar tarafindan daha önce yapılan, akıllı yapılarda insan-bina etkileşimleri üzerine potansiyel araştırma konularının değerlendirildiği (Topak et al., 2019) ve insanbilgisayar etkileşimi araştırma disiplininde yaygın olarak kullanılan araştırma metodlarının insanbina etkileşimi çalışmalarında kullanılabilirliğinin incelendiği (Topak \& Pekeriçli, 2020) araştırmaların devamı niteliğinde olan bu çalışmada, binalardaki teknolojik dönüşüm akıllı binalar terimi üzerinden gözden geçirilmiş, konvansiyonel yapılardaki insan-bina etkileşimleri incelenmiş ve geleceğin yapılarındaki arayüz dönüşümü üzerine bir çerçeve sunulmuştur. $\mathrm{Bu}$ çerçeve üzerinden, gelecek araştırmalarda, farklı bina-insan etkileşimine olanak sağlayabilecek yeni teknolojik ürünlerin, katılımcı bireyler ile birlikte kontrollü deneyler yapılarak değerlendirilmesi, ve bu doğrultuda insan-arayüz ilişkisinin ortaya çıkardığı çeşitli parametrelerin belirlenmesi planlanmaktadır. Her ne kadar bu konulardaki araştırmalar ne literatürde ne de pratikte henüz çok olgun seviyelere ulaşamamış olsa da, bilgi teknolojilerinin günümüzde yakaladığı ivme göz önüne alındığında, öngörülen dönüşümün çok da uzak olmayan bir gelecekte tezahür edeceği düşünülmektedir.

\section{REFERANSLAR (REFERENCES)}

Alavi, H. S., Churchill, E. F., Lalanne, D., Dalsgaard, P., Fatah, A., Schieck, G., ... Rogers, Y. (2019). Introduction to Human-Building Interaction (HBI): Interfacing HCI with Architecture and Urban Design. ACM Transactions on Computer-Human Interaction, 26(6). https://doi.org/10.1145/3309714

Andersen, R. (2012). The influence of occupants ' behaviour on energy consumption investigated in 290 identical dwellings and in 35 apartments. 10th International Conference on Healtby Buildings, 1-3. 
Bader, P., Voit, A., Le, H. V., Wozniak, P. W., Henze, N., \& Schmidt, A. (2019). WindowWall: Towards Adaptive Buildings with Interactive Windows as Ubiquitous Displays. TOCHI: Special Issue on Human-Building Interaction, 26(2).

Banham, R. (1969). The Architecture of the Well-Tempered Environment. University of Chicago Press.

Chen, H. M., Lin, C. W., Hsieh, S. H., Chao, H. F., Chen, C. S., Shiu, R. S., ... Deng, Y. C. (2012). Persuasive feedback model for inducing energy conservation behaviors of building users based on interaction with a virtual object. Energy and Buildings, 45, 106-115. https://doi.org/10.1016/j.enbuild.2011.10.029

Chen, Y., \& Treado, S. (2014). Development of a simulation platform based on dynamic models for HVAC control analysis. Energy and Buildings, 68, 376-386. https://doi.org/10.1016/J.ENBUILD.2013.09.016

Clements-Croome, D. J. (2013). Intelligent Buildings: Design, management and operation (2nd ed.). ICE Publishing.

D’Oca, S., Hong, T., \& Langevin, J. (2018). The human dimensions of energy use in buildings: A review. Renewable and Sustainable Energy Reviews, 81, 731-742. https://doi.org/10.1016/j.rser.2017.08.019

Dalton, N. S., Schnädelbach, H., Wiberg, M., \& Varoudis, T. (2004). Architecture and Interaction: Human Computer Interaction in Space and Place (Vol. 6). https://doi.org/10.1007/s10111-0030139-6

EIA. (2017). World Energy Outlook 2017. U.S. Energy Information Administration.

EU GDPR (2020). Retrieved from https://gdpr.eu/ , accessed on December $15^{\text {th }}, 2020$.

Frontczak, M., Schiavon, S., Goins, J., Arens, E., Zhang, H., \& Wargocki, P. (2012).

Quantitative relationships between occupant satisfaction and satisfaction aspects of indoor environmental quality and building design. Indoor Air, 22(2), 119-131.

https://doi.org/10.1111/j.1600-0668.2011.00745.x

Grabe, J. Von, \& Gonzalez, C. (2016). Human Decision Making in Energy-Relevant Interaction with Buildings. In Central European Symposium on Building Physics. Dresden.

Hong, T., D’Oca, S., Taylor-Lange, S. C., Turner, W. J. N., Chen, Y., \& Corgnati, S. P. (2015). An ontology to represent energy-related occupant behavior in buildings. Part II: Implementation of the DNAS framework using an XML schema. Building and Environment, 94(P1), 196-205. https://doi.org/10.1016/j.buildenv.2015.08.006

Hong, T., D’Oca, S., Turner, W. J. N., \& Taylor-Lange, S. C. (2015). An ontology to represent energy-related occupant behavior in buildings. Part I: Introduction to the DNAs framework. Building and Environment, 92(P1), 764-777.

https://doi.org/http://dx.doi.org/10.1016/j.buildenv.2015.02.019

Hong, T., Yan, D., D’Oca, S., \& Chen, C. F. (2017). Ten questions concerning occupant behavior in buildings: The big picture. Building and Environment, 114, 518-530. https://doi.org/10.1016/j.buildenv.2016.12.006 
Indraganti, M., \& Rao, K. D. (2010). Effect of age, gender, economic group and tenure on thermal comfort: A field study in residential buildings in hot and dry climate with seasonal variations. Energy and Buildings, 42(3), 273-281.

https://doi.org/10.1016/j.enbuild.2009.09.003

IPCC. (2015). Climate change 2014: mitigation of climate change. Cambridge University Press.

Këpuska, V., \& Bohouta, G. (2018). Next-generation of virtual personal assistants (Microsoft Cortana, Apple Siri, Amazon Alexa and Google Home). In 2018 IEEE 8th Annual Computing and Communication Workshop and Conference - CCWC 2018 (pp. 99-103).

Khashe, S., Heydarian, A., Becerik-Gerber, B., \& Wood, W. (2016). Exploring the effectiveness of social messages on promoting energy conservation behavior in buildings. Building and Environment, 102, 83-94. https://doi.org/10.1016/j.buildenv.2016.03.019

Klein, L., Kwak, J. Y., Kavulya, G., Jazizadeh, F., Becerik-Gerber, B., Varakantham, P., \& Tambe, M. (2012). Coordinating occupant behavior for building energy and comfort management using multi-agent systems. Automation in Construction, 22, 525-536. https://doi.org/10.1016/j.autcon.2011.11.012

Konstantakopoulos, I. C., Barkan, A. R., He, S., Veeravalli, T., Liu, H., \& Spanos, C. (2019). A deep learning and gamification approach to improving human-building interaction and energy efficiency in smart infrastructure. Applied Energy, 237(December 2018), 810-821. https://doi.org/10.1016/j.apenergy.2018.12.065

Kwong, Q. J., Adam, N. M., \& Sahari, B. B. (2014). Thermal comfort assessment and potential for energy efficiency enhancement in modern tropical buildings: A review. Energy and Buildings, 68, 547-557. https://doi.org/10.1016/J.ENBUILD.2013.09.034

Lazarova-Molnar, S., \& Mohamed, N. (2017). On the Complexity of Smart Buildings Occupant Behavior: Risks and Opportunities. Proceedings of the 8th Balkan Conference in Informatics. https://doi.org/10.1145/3136273.3136274

Lee, J. (2010). Conflict resolution in multi-agent based Intelligent Environments. Building and Environment, 45(3), 574-585.

Lilis, G., Conus, G., Asadi, N., \& Kayal, M. (2017). Towards the next generation of intelligent building: An assessment study of current automation and future IoT based systems with a proposal for transitional design. Sustainable Cities and Society, 28, 473-481.

https://doi.org/10.1016/j.scs.2016.08.019

Masoso, O. T., \& Grobler, L. J. (2010). The dark side of occupants' behaviour on building energy use. Energy and Buildings, 42(2), 173-177. https://doi.org/10.1016/j.enbuild.2009.08.009

Nembrini, J., \& Lalanne, D. (2017). Human-Building Interaction: When the Machine Becomes a Building. In INTERACT 2017 (Vol. 10514, pp. 534-543). https://doi.org/10.1007/978-3319-67684-5

Nicol, J. F., \& Humphreys, M. A. (2002). Adaptive thermal comfort and sustainable thermal standards for buildings. Energy and Buildings, 34(6), 563-572. https://doi.org/10.1016/S0378-7788(02)00006-3 
Park, J. Y., \& Nagy, Z. (2018). Comprehensive analysis of the relationship between thermal comfort and building control research - A data-driven literature review. Renewable and Sustainable Energy Reviews, 82(September 2017), 2664-2679.

https://doi.org/10.1016/j.rser.2017.09.102

Schweiker, M. (2010). Occupant Behaviour and the Related Reference Levels for Heating and Cooling. Tokyo City University.

Thomas, S., \& Pasquier, S. B. (2015). Energy efficiency, buildings and behaviour workshop. IEA Publications.

Topak, F., Pekeriçli, M. K., Tanyer, A.M. (2019). Human-Building Interactions in Intelligent Built Environments. II. International Conference and Exhibition on Digital Transformation \& Smart Systems - DTSS 2019, Ankara, Turkey.

Topak, F., \& Pekeriçli, M. K. (2020). Towards Using Human-Computer Interaction Research for Advancing Intelligent Built Environments : A Review. 6th International Project and Construction Management Conference - IPCMC 2020.

U.S. Department of Energy. (2011). Building Energy Data Book.

Wang, S. (2010). Intelligent Buildings and Buildings Automation. New York: Spon Press.

Wigginton, M., \& Harris, J. (2002). Inteligent Skins. Oxford: Architectural Press.

Wright, D., Gutwirth, S., Friedewald, M., Vildjiounaite, E., \& Punie, Y. (Eds.). (2008).

Safeguards in a world of ambient intelligence (Vol. 1). Springer Science \& Business Media.

Yang, R., \& Wang, L. (2012). Multi-objective optimization for decision-making of energy and comfort management in building automation and control. Sustainable Cities and Society, 2(1), 1-7. https://doi.org/10.1016/J.SCS.2011.09.001.

\section{ÇIKAR ÇATIŞMASI BEYANI} (CONFLICT OF INTEREST STATEMENT )

*Bu çalışmada herhangi bir finansman kaynağı kullanılmamıştır.

\section{YAZAR KATKI BİLDİRİMİ (AUTHOR CONTRIBUTION STATEMENT)}

Araştırma Fatih Topak tarafından yapılmış, Mehmet Koray Pekeriçli tarafından yönetilmiştir.

\section{YAZARLARIN BIYYOGRAFİLERİ (BIOGRAPHIES OF THE AUTHORS)}

\section{Fatih Topak}

Fatih Topak 2013 yılında ODTÜ Mimarlık Bölümü’nde lisans eğitimini tamamladı. 2016 yllında aynı üniversitenin Yapı Bilimi programından yüksek lisans derecesini aldı. 2016 y1lında aynı programda başladığı doktora eğitimine hâlen devam etmektedir. 2014 tarihinden bu yana ODTÜ 
Mimarlık Bölümü’nde araştırma görevlisi olarak görev yapmaktadır. Araştırma ilgi alanları arasında mimarlıkta bilgi teknolojileri, akıllı yapılar, enerji verimliliği ve yapılı çevrede insan davranışları gibi konular yer almaktadır.

\section{Dr. Mehmet Koray Pekeriçli}

Dr. Mehmet Koray Pekeriçli 2000 yllında ODTÜ Mimarlık Bölümü'nde lisans derecesini tamamladı. Daha sonra TEV ve İngiliz Hükümeti ortak bursu ile gittiği İngiltere'de 2002 yllinda Reading Üniversitesi'nden Yapım Yönetimi alanında yüksek lisans derecesini aldı. 2003 yılında NSF ve YÖK ortak bursu ile gittiği A.B.D.'de Carnegie Mellon Üniversitesi'nde İnşaat Mühendisliği alanında doktora çalışmalarını yürüttü. Doktora derecesini 2006 yılında EPSRC destekli bir projede çalışmak üzere geri döndüğü İngiltere'de Reading Üniversitesi'nden 2011 yllında aldı. Bu tarihten beri ODTÜ Mimarlık Bölümü'nde öğretim üyesi olarak görev yapmaktadır. Araştırma ilgi alanları arasında Yapı Bilgi Modellemesi, Yapım Yönetimi, İnşaat Enformatiği, Yenilikçi Çözümler, ve Sürdürülebilirlik konuları yer almaktadır. 